\title{
A nova teoria da antropologia da civilização: tradução para a língua inglesa de neologismos terminológicos criados por Darcy Ribeiro nas obras 0 processo civilizatório e $\boldsymbol{O}$ povo brasileiro The New Theory of Social Anthropology of Civilization: English Translation of Terminological Neologisms created by Darcy Ribeiro in the works The Civilizational Process and The Brazilian People
}

\author{
Talita Serpa* \\ Diva Cardóso de Camargo **
}

RESUMO: Este artigo tem por objetivo investigar o processo tradutório para o inglês de termos e expressões neológicos em duas obras do antropólogo Darcy Ribeiro e nas traduções realizadas respectivamente por Betty J. Meggers e Gregory Rabassa. Para tanto, fundamenta-se nos Estudos da Tradução baseados em Corpus (BAKER, 1995, 1996, 2000; CAMARGO, 2007), na Linguística de Corpus (BERBER SARDINHA, 2004) e, em parte, na Terminologia (ALVES, 1999; BARROS, 2004; BOULANGER, 1989; CABRÉ, 1993, 1999). Nota-se que os termos empregados não apresentam univocidade dentro da linguagem da Antropologia Brasileira, tendo sido necessário, ao autor, buscar alternativas terminológicas, criando conceitos novos que passaram a ser utilizados por outros antropólogos. Ao serem traduzidos, os termos e expressões desenvolvidos nos textos originais refletiram uma elaboração neológica e uma variação lexical, adotadas pelos tradutores, para as possibilidades presentes na Língua Meta. Nota-se que essa tendência pode ser encontrada na tradução dos textos de Ribeiro, evidenciando as dificuldades de conceituar o universo antropológico brasileiro em língua inglesa.

PALAVRAS-CHAVE: Estudos da Tradução baseados em Corpus. Linguística de Corpus. Neologismos Terminológicos.

\begin{abstract}
This study analyzes the translation process into English of neologisms and expressions in the works written by the anthropologist Darcy Ribeiro and in their respective translations, made by Betty $\mathrm{J}$. Meggers and Gregory Rabassa. Our research project draws on Corpus-Based Translation Studies (BAKER, 1995, 1996, 2000; CAMARGO, 2007), Corpus Linguistics (BERBER SARDINHA, 2004) and on some concepts of Terminology (ALVES, 1999; BARROS, 2004; BOULANGER, 1989; CABRÉ, 1993, 1999). Results show that terms do not present similarities within the language related to Brazilian Anthropology, being necessary for the author to look up alternative terminology and to create new concepts that can be used by other anthropologists. The translation of words and expressions developed by the author reflects lexical variation due to the options chosen by the respective translators for the target language. These tendencies may be found in Ribeiro's translated texts, indicating the difficulty to conceptualize the anthropological Brazilian universe in English.
\end{abstract}

KEYWORDS: Corpus-Based Translation Studies. Corpus Linguistics. Terminological Neologisms.

\footnotetext{
* Doutoranda do Programa de Pós-Graduação em Estudos Linguísticos do IBILCE/UNESP. Professora titular do curso de Letras Tradutor e Intérprete da União das Faculdades dos Grandes Lagos/São José do Rio Preto.

** Professora aposentada da Universidade Estadual Paulista Júlio de Mesquita Filho, câmpus de São José do Rio Preto, onde atua como Professor Voluntário e faz parte do corpo de Docentes permanentes dos Programas de PósGraduação em Letras e Estudos Linguísticos.
} 


\section{Introdução}

O estudo antropológico no Brasil teve seu início com a estruturação curricular dos cursos de graduação em Ciências Sociais da Universidade de São Paulo (USP) e da Escola de Sociologia e Política (ESP), na década de 1930. As investigações que precederam a institucionalização da área no país marcavam-se pelos relatos históricos de grupos colonizadores e pelo eurocentrismo que promovia uma domesticação teórica. Com a formação das primeiras turmas, antropólogos e sociólogos brasileiros passaram a atuar no campo acadêmico e político do país, como é o caso de Darcy Ribeiro (1968, 1995), Fernando Henrique Cardoso (1996), Florestan Fernandes (1975) e Roberto DaMatta (1997), entre outros.

Dessa forma, por meio de diferentes abordagens teóricas, estes autores buscaram consolidar a análise dos fatores de desenvolvimento sociocultural da sociedade brasileira. No que concerne às pesquisas de cunho cultural, a Antropologia destacou-se, principalmente, por meio da proposta de desvinculação das leituras anteriores e da criação de modelos investigativos pautados nos fenômenos e na organização dos povos nacionais, os quais foram adotados por Darcy Ribeiro.

De acordo com o pesquisador, os estudos realizados no Brasil não apresentavam, ainda, uma

[...] teoria geral, cuja luz nos tornasse explicáveis em seus próprios termos, fundida em nossa experiência histórica. As teorizações oriundas de outros contextos eram todas elas eurocêntricas demais e, por isso mesmo, impotentes para nos fazer inteligíveis. Nosso passado, não tendo sido o alheio, nosso presente não era necessariamente o passado deles, nem nosso futuro um futuro comum. (RIBEIRO 1995, p.13)

O autor passou, então, a concentrar a análise antropológica nacional em dois focos principais: a questão dos índios e negros e a formação da identidade do brasileiro, criando, assim, uma série de seis livros intitulada Antropologia da Civilização (doravante $A C)^{1}$, nos quais promoveu a elaboração de uma terminologia adequada aos padrões e ao ambiente social em foco e formulada com base na constituição de neologismos terminológicos.

Nesse sentido, mediante as abordagens que valorizam as relações sociais da maior nação latino-americana e que promovem uma teoria baseada nos processos culturais e humanos do Brasil, a tradução, na direção português $\rightarrow$ inglês, desta nova teorização faz-se necessária, com

\footnotetext{
${ }^{1}$ As publicações compreendem os trabalhos: O processo civilizatório: etapas da evolução sociocultural (1968); As Américas e a civilização (1970); Os índios e a civilização (1970); O dilema da América Latina (1971); Os brasileiros (1972); e O povo brasileiro: a formação e o sentido do Brasil (1995).
} 
o objetivo de proporcionar a divulgação dos trabalhos de Ribeiro em nível internacional, elevando a categoria da produção científica de antropólogos brasileiros fora do país.

No entanto, são inexistentes investigações sobre o uso de termos e expressões cunhados pelo autor em suas obras, evidenciando a necessidade de observar a natureza deste tipo de texto de especialidade, assim como da tradução desta nova terminologia presente na teoria de Ribeiro.

Por tal razão, esta investigação utiliza-se das teorias propostas para os Estudos da Tradução baseados em Corpus (BAKER, 1995, 1996, 2000; CAMARGO, 2005) e para a Linguística de Corpus (BERBER SARDINHA, 2004), a fim de verificar as escolhas lexicais feitas por Meggers e Rabassa nas traduções dos livros O processo civilizatório (1968) e O povo brasileiro (1995), no que diz respeito aos neologismos darcynianos, assim como busca investigar as tendências linguísticas apresentadas por estes tradutores no que concerne aos termos e expressões que descrevem a sociedade brasileira, enfatizando as relações de significado que se estabelecem entre as teorias das obras, por meio do léxico, e as dissociações de conceitos ocorrentes no ato tradutório.

Com isso, pretende-se fornecer subsídios para o desenvolvimento de glossários bilíngues de Antropologia Brasileira, assim como para a análise das possíveis variações lexicais dentro de uma terminologia nascente, com sentidos distintos entre as diferentes culturas.

\section{Fundamentação Teórica}

Ao propor a abordagem teórico-metodológica para os Estudos da Tradução baseados em Corpus, Baker $(1995,1996,2000)$ assume uma posição de liderança na área. Para desenvolver seu trabalho, a teórica fundamenta-se nos Estudos Descritivos da Tradução, com base nos trabalhos de Even-Zohar (1978) e de Toury (1978). A autora também se apoia nas investigações de Sinclair (1991), no tocante ao aporte teórico da Linguística de Corpus e ao uso de corpora eletrônicos e ferramentas computacionais para a realização de pesquisas nos textos meta (TMs).

Para a investigadora (1993),

[...] textos traduzidos registram eventos comunicativos genuínos e como tais não são nem inferiores nem superiores aos outros eventos comunicativos em qualquer língua. Entretanto, eles são diferentes, e a natureza dessa diferença precisa ser explorada e registrada. ${ }^{2}$ (BAKER, 1993, p. 234)

\footnotetext{
2 Translated texts record genuine communicative events and as such are neither inferior nor superior to other communicative events in any language. They are however different, and the nature of this difference needs to be explored and recorded.
} 
Baker (1995) apresenta, ainda, sua concepção de corpus na qual explicita a preferência pela análise por meio de computador:

[...] corpus é um conjunto de textos naturais (em oposição a exemplos/sentenças), organizados em formato eletrônico, passíveis de serem analisados, preferencialmente, em forma automática ou semi-automática (em vez de manualmente). ${ }^{3}$ (BAKER, 1995, p. 226)

A Linguística de Corpus caracteriza-se por seu caráter transdisciplinar e pela possibilidade de análise de grandes quantidades de informações. Fundamenta-se em bases empiristas, considerando a linguagem como um sistema probabilístico. Para Berber Sardinha (2004), “[...] a visão da linguagem como sistema probabilístico pressupõe que, embora muitos traços linguísticos sejam possíveis teoricamente, não ocorrem com a mesma frequência" (BERBER SARDINHA, 2004, p. 30).

A frequência de ocorrência de vocábulos e expressões apresenta certa regularidade, o que permite que seja mapeada de acordo com o contexto de uso. Dessa forma, no âmbito da tradução, é possível delinear, por meio da análise de corpora, quais os traços mais recorrentes no processo tradutório de uma língua à outra. Berber Sardinha $(2004$, p. 31) também destaca que a linguagem é padronizada e não um conjunto de escolhas aleatórias de indivíduos isolados.

A Linguística de Corpus assume, dessa forma, importante papel no levantamento e estudo dos usos de elementos recorrentes às linguagens, fornecendo o aparato teóricometodológico para análises linguísticas em diversas áreas de especialidade, incluindo os processos de composição terminológica e de tradução. Dentro desse campo, autores como Camargo, Paiva e Xatara (2008), Orenha (2009), Orenha e Rocha (2012), Paiva (2007), Sabino (2011) e Tagnin (2012), atualmente, promovem o desenvolvimento de pesquisas cujo uso de corpora é voltado à observação de fraseologismos, estruturas complexas, colocações, termos e expressões especializadas, entre outros fenômenos.

Nota-se, por conseguinte, a possível intersecção entre as bases teóricas dos estudos com base em corpus e alguns pressupostos da Terminologia, principalmente no tocante à tradução, visto que as teorias terminológicas tendem a fornecer o material necessário à atividade tradutória, de modo que os profissionais da área passam a contar com o acesso rápido aos termos apropriados dos mais diversos campos de produção técnico-científica. Sendo assim, serão

\footnotetext{
${ }^{3}[\ldots]$ corpus mean[s]any collection of running texts (as opposed to examples/sentences), held in electronic form and analysable automatically or semi-automatically (rather than manually).
} 
observados termos especializados entendidos como a "designação, por meio de uma unidade linguística, de um conceito definido em uma língua de especialidade” (ISO 1087, 1990, p.5, apud BARROS, 2004, p.40).

Quanto às expressões fixas, adota-se a definição de Baker (1992), para quem se tratam de expressões consagradas, referentes a determinado tipo de texto, e que permitem pouca ou nenhuma variação. No caso das expressões semifixas, Camargo (2005) aponta que essas apresentam maior variação e carregam consigo todo um contexto, podendo ser consideradas específicas de determinada língua de especialidade.

Dessa forma, tendo por base a abordagem teórico-metodológica dos Estudos da Tradução baseados em Corpus (BAKER, 1996, 2004), bem como os procedimentos da Linguística de Corpus (BERBER SARDINHA, 2004) e da Terminologia (BARROS, 2004), passa-se a procurar por possíveis padrões recorrentes e por preferências adotadas pelos tradutores da subárea de Antropologia, evidenciando a existência de características semelhantes e divergentes na modalidade da tradução de obras de caráter socioantropológico. No entanto, é importante ressaltar que, embora os pressupostos da Terminologia que norteiam a busca de traduções adequadas às distintas áreas de especialidade sejam os da padronização, a ideia de variação terminológica precisa ser levada em consideração quando tratamos especialmente de texto como os das Ciências Sociais.

Barros (2004) acrescenta que cada povo recorta a realidade objetiva de maneira distinta e que as debilitações conceituais das representações sociais são designadas por unidades lexicais que, consideradas como signos de domínios específicos da atividade da comunidade sociocultural, podem ser afirmadas como unidades terminológicas. A teórica debruça-se sobre a questão antropológica da descrição do sistema cultural de um povo e afirma haver a necessidade da construção de um conjunto terminológico específico para essa área. Verificase, portanto, que cada antropólogo delimita seu campo de estudo e procura conhecer as nomeações dos seus objetos de análise.

Dessa forma, pode-se dizer que nas Ciências Sociais, além de uma terminologia científica própria à constituição de conceitos acadêmicos, existe também a necessidade de se considerar a nomenclatura dos elementos sociais investigados. Por conseguinte, as subáreas das Ciências Sociais apresentam um vocabulário especializado com a criação de conceitos teóricos que assumem características próprias dentro da obra de cada cientista social. Contudo, a maioria 
dos estudiosos dedica-se a fenômenos socioculturais específicos e, com isso, os fatos e elementos da sociedade sob pesquisa tornam-se parte da Terminologia daquele autor.

A pesquisa proposta foca na produção dos chamados neologismos terminológicos nas Ciências Sociais, principalmente quando se tratam de características intrínsecas a um povo específico, como no caso dessa pesquisa, a cultura e o povo brasileiro.

Segundo Boulanger (1989), os neologismos terminológicos são desenvolvidos sob condições sociais e culturais determinadas institucionalmente dentro das áreas de especialidade de que fazem parte. $\mathrm{O}$ autor apresenta determinadas condutas a serem seguidas para a criação neológica. Dessa forma, os termos podem: 1) denominar um conceito estável, previamente delimitado de forma clara; 2) ser concisos e breves; 3) ser construídos de acordo com as regras do próprio sistema linguístico; 4) constituir base de séries de palavras derivadas; e 5) adaptarse ao sistema fonológico e ortográfico da língua.

Por sua vez, Cabré (1993) propõe, ainda, as seguintes condições para os neologismos terminológicos: 1) ser fruto de uma efetiva necessidade denominativa; 2) não apresentar conotações negativas nem provocar associações inconvenientes; e 3) pertencer a um registro formal de especialidade.

De acordo com Alves (1999, p.75), as criações neológicas nos campos de especialidade são motivadas, pois correspondem a uma necessidade ditada pelo desenvolvimento das ciências e das técnicas. A elaboração desses elementos deve, portanto, obedecer a algumas normas, como a conformidade com as regras de formação morfológica e a possibilidade de derivação de novos elementos. Assim sendo, os neologismos terminológicos apontam um caráter relativamente estável da língua.

Assim, é importante que o processo tradutório de tal repertório terminológico, segundo o Guia para Tradução de textos de Ciências Sociais (2006), elaborado por Michael Henry Heim \& Andrzej W. Tymowski, pesquisadores do American Council of Learned Societies, siga alguns direcionamentos, visto que os textos das áreas antropológica e sociológica são distintos dos demais textos científicos por não poderem ser generalizados e estarem submetidos a contextos sociais, políticos e culturais distintos, de acordo com o país e as tradições e costumes que o constituem.

Embora afirmem que essa submissão a fatores sociais específicos de determinadas culturas gere inconsistência terminológica, não deixam de observar que:

Um termo-chave que ocorre mais de uma vez pode ser traduzido pela mesma palavra sempre, mas o tradutor precisa primeiramente determinar se o 
significado é de fato o mesmo. Se não for, o tradutor pode escolher outra palavra, mas a decisão deve ser consciente. Para estabelecer consistência à tradução, o editor pode sugerir que os tradutores elaborem um glossário de termos-chave quando trabalham com um texto específico. ${ }^{4}$ (HEIM; TYMOWSKI, 2006, p.10)

Os cientistas sociais, ao introduzirem novos conceitos, geralmente atuam para que as palavras ou expressões empregadas sejam aceitas pela comunidade científica e se universalizem para o seu público, passando a constituir termos. Bons exemplos disso são a ninguendade e a transfiguração étnica de Darcy Ribeiro. Os conceitos que transmitem são, em geral, culturalmente determinados, mas a opção por termos técnicos é um aspecto dessas ciências e, por isso, é importante que os tradutores estejam atentos no momento de vertê-los para as Línguas Metas (LMs).

Embora não seja possível generalizar, os dois principais procedimentos utilizados pela maioria dos tradutores, de acordo com Heim e Tymowski (op.cit. p.10), são: (1) empréstimo da língua original; e (2) tradução literal para o termo. Ambos causam um estranhamento inicial no leitor alvo, pois ou estão em língua estrangeira ou forçam a forma original da LM a uma forma que não lhe é natural. No entanto, frequentemente, as línguas se adaptam e absorvem os "estrangeirismos" e "literalidades" 5 .

É importante para o tradutor que se depara com um texto antropológico a ser traduzido estar familiarizado com esse tipo de redação e também com os termos mais adequados a cada subárea das Ciências Sociais. Essa é uma das condições apontadas pelos autores do Guia, por facilitar que os textos sejam publicados de acordo com padrões internacionais. Tanto os tradutores e pesquisadores da área quanto os estudantes de Tradução estariam diretamente beneficiados com os resultados de trabalhos voltados para esses propósitos ${ }^{6}$.

\footnotetext{
${ }^{4}[\ldots]$ a key term that occurs more than once should be translated by the same word each time, but the translator must first determine whether the meaning is in fact the same. If it is not, the translator may choose another word, but the decision must be a conscious one. To foster consistency, the editor can suggest that translators create a personal glossary of key terms as they work through a text.

${ }^{5}$ A discussão acerca de procedimentos técnicos de tradução é polêmica, pois não existe um consenso entre os teóricos da Tradução, os quais ora consideram o "empréstimo" e a "tradução literal"como técnicas tradutórias (DUTRA, 1984) ora como modalidades de tradução (AUBERT, et.al., 1984; CAMARGO, 1993). Tais processos também são classificados como estratégias de tradução (CHESTERMAN, 1997) e como métodos tradutórios (SCHLEIERMACHER, 2001), entre outras nomenclaturas. Sendo assim, a criação de um Guia para a tradução de termos das Ciências Sociais talvez não abarque tais controvérsias.

${ }^{6}$ É importante salientar que diante dos avanços dos Estudos da Tradução que se voltam para uma atuação autônoma e para uma postura emancipada do tradutor, um Guia de escolhas a serem realizadas durante o processo tradutório assume, na melhor das hipóteses, uma intenção prescritiva.
} 


\section{Material e Método}

Para esta investigação, foram compilados os seguintes corpora: 1) um subcorpus principal paralelo de Antropologia, constituído pelas obras: O processo civilizatório, de autoria de Darcy Ribeiro, publicada originalmente em português no ano de 1968 (total de itens: 63.159), e a respectiva tradução para o inglês, realizada por Betty J. Meggers sob o título The Civilizational Process, publicada em 1968 (total de itens: 53.464); e $O$ povo brasileiro: a formação e o sentido do Brasil, de autoria de Darcy Ribeiro, publicada originalmente em português, no ano de 1995 (total de itens: 115.474), e a respectiva tradução para o inglês, realizada por Gregory Rabassa, sob o título The Brazilian People: formation and meaning of Brazil, publicada em 2000 (total de itens: 139.858); 2) um corpus comparável de controle, composto por 15 obras das subáreas de Antropologia Social e Cultural escritas originalmente em português (total de itens: 1.250.434); e 3) um corpus comparável de controle, composto por 15 obras das subáreas de Antropologia Social e Cultural escritas originalmente em inglês (total de itens: 2.257.474).

As obras que compõem o corpus comparável em português representam publicações de pesquisas relacionadas à constituição do povo brasileiro, de autoria de Gilberto Freyre, Eduardo Viveiros de Castro, Marcio Goldman e Roberto DaMatta, publicadas entre as décadas de 30 e 90 do século XX.

Para a formação do corpus comparável em inglês, foram utilizados textos clássicos da Antropologia Britânica, como por exemplo, de autores como Bronislaw Malinowski, RadcliffeBrown e Mary Douglas; e da Antropologia Americana, como de Margaret Mead e Franz Boas, publicados entre os séculos XIX e XX. Cabe salientar que as obras destes autores constam da bibliografia utilizada para a composição das teorias de Darcy Ribeiro.

Também foram utilizados dois corpora de referência para a extração de palavras-chave. Em português, utilizou-se o corpus Lácio-Ref, composto de textos em português brasileiro, escritos respeitando-se a norma culta. Para a extração de palavras-chave em inglês, utilizou-se o British National Corpus (BNC Sampler), composto por textos originalmente escritos em inglês.

Quanto aos procedimentos adotados para o tratamento do corpus de estudo, as obras escolhidas foram digitalizadas, limpas e salvas em Word. Em seguida, os livros foram salvos como texto sem formatação (txt), a fim de serem processados pelo programa WordSmith Tools, criado por Scott (1999). 
No tocante às ferramentas disponibilizadas pelo programa, esta pesquisa emprega a KeyWords e a Concord, assim como os respectivos aplicativos (colocados e clusters).

\section{Análise e discussão dos resultados}

Para o levantamento de termos simples, expressões fixas e semifixas de $A C$ foram selecionados os vocábulos de maior chavicidade ${ }^{7}$ de base substantival e adjetival do subcorpus de estudo.

A análise da obra $O$ processo civilizatório foi realizada por meio das listas de palavraschave extraídas com o auxílio da ferramenta Keywords. Foram geradas as listas de palavraschave do subcorpus de textos fonte (TF), tomando para contraste o corpus de referência LácioRef. Após este levantamento foram também observadas as palavras-chave a partir do TM, tendo como corpus de referência o BNC Sampler. Apresentam-se, a seguir, as Tabelas 1 e 2 com as dez palavras-chave no TF e no TM.

Tabela 1: Lista das dez palavras-chave a partir do subcorpus principal da obra $O$ processo civilizatório.

\begin{tabular}{l|l|l|l}
\hline 1. Sociedades & 4. Revolução & 7. Desenvolvimento & 10. Impérios \\
2. Povos & 5. Processo & 8. Poder & \\
3. Social & 6. Sistema & 9. Produção & \\
\hline
\end{tabular}

Tabela 2: Lista das dez palavras-chave a partir do subcorpus principal da obra The Civilizational Process.

\begin{tabular}{l|l|l|l}
\hline 1. Socialism & 4. Subsistence & 7. Industrialization & 10. Collectivist \\
2. Socialist & 5. Feudalism & 8. Tribal & \\
3. Sectors & 6. Export & 9. Conquest & \\
\hline
\end{tabular}

Para dar suporte à seleção de tais dados, realizou-se uma consulta a um corpus de apoio formado por dicionários das subáreas das Ciências Sociais, a saber: Antropologia, Ciência Política, Economia e Sociologia, com o objetivo de confirmar sua inclusão ou exclusão nas análises.

Da mesma forma, foram realizadas investigações semelhantes para o subcorpus da obra O povo brasileiro. A seguir, apresentam-se as Tabelas 3 e 4 com as dez palavras-chave do TFs e do TM.

\footnotetext{
${ }^{7}$ Compreendemos por chavicidade a relação estatística entre a ocorrência de dada palavra em um corpus de estudo e a importância que assume para o léxico de uma área de especialidade.
} 
Tabela 3: Lista das dez palavras-chave a partir do subcorpus principal da obra O povo brasileiro.

\begin{tabular}{l|l|l|l}
\hline 1. Índios & 4. Sociedade & 7. Gente & 10. Escravos \\
2. População & 5. Negros & 8. Povo & \\
3. Terra & 6. Brasileiros & 9. Economia & \\
\hline
\end{tabular}

Tabela 4: Lista das dez palavras-chave a partir do subcorpus principal da obra The Brazilian People

\begin{tabular}{l|l|l|l}
\hline 1. Indians & 4. Population & 7. World & 10. Slaves \\
2. People & 5. Land & 8. Order & \\
3. Brazilian & 6. Social & 9. Society & \\
\hline
\end{tabular}

Notou-se que as listas de palavras-chave destacaram a representatividade do subcorpus, uma vez que apresentavam as palavras de maior chavicidade a partir de um corpus de referência com mais de um milhão de palavras, o que indica uso frequente de palavras apontadas como fortes candidatas a termos na subárea de $A C$. Tal resultado mostra a validade de um levantamento de termos com a metodologia da Linguística de Corpus e da Terminologia, dado que auxiliou no refinamento das listas apresentadas neste trabalho, as quais poderão assessorar o tradutor ao lidar com textos específicos de Ciências Sociais. Os dados apontam uma diferença na tradução terminológica na subárea em análise, mostrando que os tradutores optaram por algumas escolhas léxicas distintas ao levarem os estudos de Darcy Ribeiro para o público alvo, o qual apresentava um caráter teórico mais eurocêntrico. No entanto, a maioria dos candidatos a termos observados apresentou traduções semelhantes em ambas as obras em língua inglesa, como, por exemplo, em: "desenvolvimento" $\rightarrow$ development; "povo/s" $\rightarrow$ people/s; "população/ões" $\rightarrow$ population/s; "processo/s" $\rightarrow$ process/es; e "sociedade/s" $\rightarrow$ society/ies.

Dessa maneira foi possíyel reconhecer pelo menos quatro possíveis subdivisões para a composição terminológica em $A C$ : (1) termos relacionados aos atores de mudança social, como, por exemplo, escravos e indígenas; (2) grupos ou padrões de coletividade, no caso de populações; (3) processos e atividades sociais, como a abolição e o feudalismo; (4) locais de interação sociocultural e política, como latifúndios e fazendas.

Com base nesses dados e a partir das palavras-chave levantadas, foi realizada a observação das linhas de concordância, dos agrupamentos lexicais (clusters) e dos colocados (collocates) com a utilização da ferramenta Concord. A seguir, apresentam-se, nas Tabelas 5 e 6, cinco dos candidatos a termos em ambas as obras e as expressões por eles formadas (“povo/s", "processo/s", "índio/s", "gente/s" e "sistema/s"): 
Tabela 5: Candidatos a termos simples e expressões fixas e semifixas extraídos do subcorpus principal da obra $O$ processo civilizatório.

POVO/S - Povo Conquistado - Povos Prósperos - Povos Atrasados na História - Povos Subdesenvolvidos - Povos Inslamizados - Povos Pastoris - Povos Irânicos - Povos -Testemunho Povos Marginais - Povos Coloniais - Povos Extra-europeus - Povos Transplantados - Povos Rioplatenses - Povos Emergentes - Povos Autóctones - Povos Tribais - Povos Cêntricos - Povos Extra-imperiais - Povos Ruralizados - Povos Sedentarizados - Povos Agricultores

PROCESSO/S- Processo Civilizatório - Processo de Atualização Histórica - Processo de Modernização Reflexa - Processo de Industrialização - Processo de Restauração Imperial - Processos Produtivos

ÍNDIO/S - Índios Xavantes

GENTE/S - Gente Desenraizada

SISTEMA/S - Sistema Produtivo - Sistema Econômico - Sistema Colonial - Sistema de Intercâmbio Econômico - Sistema Político - Sistema Mercantil - Sistema Capitalista - Sistema Capitalista Mercantil - Sistema Fabril - Sistema de Lucro - Sistema Empresarial - Sistema Imperialista Sistema Sociopolítico - Sistemas de Repartição da Renda - Sistema de Exploração Externa

Tabela 6: Candidatos a termos simples e expressões fixas e semifixas extraídos do subcorpus principal da obra $O$ Povo Brasileiro.

POVO/S - Povo Brasileiro - Povo-Massa - Povo Novo - Povo Sublusitano - Povo Nascente - Povo Livre - Povo Prístino - Povo da Floresta - Povo Indígena - Poyo Mameluco - Povo-Nação - Povo Autônomo - Povos Indenes - Povos Morenos - Povos Transplantados - Povos Pré-lusitanos - Povos Testemunhos - Povos Pastoris - Povos Tribais - Povos Pré-agrícolas - Povos Germinais

PROCESSO/S - Processo Civilizatório - Processo de Gestação Étnica - Processo de Integração dos Índios - Processo de Industrialização - Processo de Integração Civilizatória - Processo Deculturativo - Processo de Fusão Racial - Processo Biótico de Consumação dos Negros - Processo Biótico de Multiplicação de Mulatos - Processo de Integração dos Índios - Processo de Reaglutinação das Populações Caipiras

ÍNDIO/S - Índio Nativo - Índio Comunitário - Índio Cativo - Índio Indolente - Índio Tribal - Índio Livre - Índio Arrendado - Índios Brasileiros - Índios Campineiros - Índios Capturáveis - Índios Cavaleiros - Índios Civilizados - Índios Cristãos - Índios de Corso - Índios de Guerra - Índios de Vida Tribal - Índios Destribalizados - Índios Escravizados - Índios Escravos - Índios Flecheiros Índios Genéricos - Índios Hostis - Índios Isolados - Índio Missioneiro - Índios Missioneiros Desvirilizados - Índios Sedentarizados - Índios Silvícolas

GENTE/S - Gente da Terra - Gentes Deculturadas - Gentes Destribalizadas - Gente Fidalga - Gente Índia - Gente Livre - Gente Mestiça - Gente Mestiçada - Gente Multiétnica - Gente Recém-feita

SISTEMA/S - Sistema Pastoril - Sistema Empresarial Privado - Sistema Senhorial do Latifúndio Pastoril - Sistema Produtivo - Sistema Mercantil - Sistema Fundiário - Sistema de Fazendas Sistema de Parceria - Sistema Financeiro - Sistema Latifundiário - Sistema de Coivara - Sistema de Donataria - Sistema de Colonato - Sistema de Granjas - Sistema de Reduções - Sistema Granjeiro Sistema Latifundiário Primitivo

É interessante notar que algumas das expressões fixas e semifixas presentes nos subcorpora de ambas as obras revelaram-se como possíveis neologismos. Dessa forma, para confirmar a criação terminológica darcyniana, os dados levantados foram cruzados com os corpora comparáveis de textos originalmente escritos em português (TOPs) e de textos originalmente escritos em inglês (TOIs), a fim de observar sua ocorrência em textos 
antropológicos produzidos por outros autores. Abaixo se apresenta a Tabela 7, com as expressões que podem constituir neologismos de Darcy Ribeiro.

Tabela 7: Expressões fixas e semifixas extraídas dos subcorpora principais em LF as quais podem constituir neologismos terminológicos.

\begin{tabular}{c|c}
\hline $\begin{array}{c}\text { Expressões que podem constituir neologismos } \\
\text { nas obras do corpus de estudo em Língua } \\
\text { Fonte (LF) }\end{array}$ & Ocorrência dos Neologismos nos TOPs \\
\hline Povo Massa & Expressão não encontrada \\
\hline Povo Novo & Povo Novo \\
\hline Povo Moreno & Expressão não encontrada \\
\hline Povos Testemunho & Expressão não encontrada \\
\hline Povos Transplantados & Expressão não encontrada \\
\hline Povos Germinais & Expressão não encontrada \\
\hline Processo Biótico de Consumação dos Negros & Expressão não encontrada \\
\hline Processo Biótico de Multiplicação de Mulatos & Expressão não encontrada \\
\hline Processo de Reaglutinação das Populações & Expressão não encontrada \\
Caipiras & Expressão não encontrada \\
\hline Índios Missioneiros Desvirilizados & Expressão não encontrada \\
\hline Gente Recém-Feita & Expressão não encontrada \\
\hline Sistema de Reduções & Expressão não encontrada \\
\hline Sistema Granjeiro & Expressão não encontrada \\
\hline
\end{tabular}

Em relação aos TOPs, observou-se que as expressões utilizadas pelo autor parecem constituir neologismos, visto que somente o conceito de "povo novo" consta da produção teórica de outros antropólogos brasileiros. No entanto, a limitação dos textos nos corpora comparáveis pode interferir na análise e, por tal razão, buscou-se a frequência de ocorrências das expressões na Web, apresentadas na Tabela 8:

Tabela 8: Expressões neológicas ocorrentes nos TFs com o número de frequência na Web.

\begin{tabular}{c|r}
$\begin{array}{c}\text { Expressões que podem constituir } \\
\text { neologismos nas obras do corpus de estudo } \\
\text { em LF }\end{array}$ & $\begin{array}{r}\text { Frequência de ocorrência das expressões em } \\
\text { português, na Web }\end{array}$ \\
\hline Povo Massa & Não há ocorrências do conceito \\
\hline Povo Novo & 214.000 \\
\hline Povo Moreno & 2.370 \\
\hline Povos Testemunho & 15 \\
\hline Povos Transplantados & 2 \\
\hline Povos Germinais & 428 \\
\hline
\end{tabular}




\begin{tabular}{c|r}
\hline Processo de Gestação Étnica & 253 \\
\hline Processo Biótico de Consumação dos Negros & 3 \\
\hline Processo Biótico de Multiplicação de Mulatos & 2 \\
\hline Processo de Reaglutinação das Populações & 3 \\
Caipiras & 2 \\
\hline Índios Missioneiros Desvirilizados & 4 \\
\hline Gente Recém-Feita & 9.730 \\
\hline Sistema de Reduções & 8 \\
\hline Sistema Granjeiro &
\end{tabular}

De acordo com os dados, constatou-se que, embora em alguns momentos as expressões tenham aplicabilidade em outros contextos de produção textual, como, por exemplo, em: "povo novo"; "sistema de granjas" e "sistema de reduções", os quais têm grande número de ocorrências; na maior parte dos casos, quando relacionadas à teoria antropológica e/ou sociológica, voltam-se para os conceitos desenvolvidos por Darcy Ribeiro, constituindo neologismos terminológicos. Sendo assim, em seus pressupostos teóricos, Darcy Ribeiro constrói a noção de um "povo novo" e o define como a confluência da regência dos portugueses com as matrizes raciais díspares e as tradições culturais distintas, de modo que estas se fundem para dar lugar a uma nova formação populacional, um novo modelo de estruturação societária. Para o autor, este povo é novo porque se diferencia de suas bases formadoras, sendo fortemente mestiçado e dinamizando uma cultura sincrética:

Povo novo, ainda, porque é um novo modelo de estruturação societária, que inaugura uma forma singular de organização sócio-econômica, fundada num tipo renovado de escravismo e numa servidão continuada ao mercado mundial. Novo, inclusive, pela inverossímil alegria e espantosa vontade de felicidade, num povo tão sacrificado, que alenta e comove a todos os brasileiros (RIBEIRO, 1995, p.19).

Esse conceito contrasta com outra ideia desenvolvida pelo autor, a de "povos testemunhos", ou seja, grupos populacionais das colônias latino-americanas que assistiram a invasão dos europeus sem perder a formação cultural e a integridade nacional. No Brasil, o teórico observa ainda que o processo civilizatório se constituiu pela recepção de "povos transplantados", os quais representaram uma "identidade étnica" perfeitamente definida na Europa e que encontraram facilidades de incorporar-se a uma nova "civilidade", surgida no seio das "matrizes negras e indígenas".

Tendo por base tais proposições, observam-se, na Tabela 9, as traduções apresentadas por Meggers e Rabassa e as constituições neológicas para as expressões em LM: 
Tabela 9: Exemplos de traduções de expressões neológicas darcynianas apresentados por Meggers e Rabassa

\begin{tabular}{|c|c|}
\hline $\begin{array}{c}\text { Expressões que podem constituir } \\
\text { neologismos nas obras do corpus de estudo } \\
\text { em LF }\end{array}$ & $\begin{array}{c}\text { Traduções realizadas por Betty J. Meggers } \\
\text { e Gregory Rabassa }\end{array}$ \\
\hline Povo Massa & Mass of People \\
\hline Povo Novo & New People \\
\hline Povo Moreno & Darker People \\
\hline Povos Testemunho & $\begin{array}{c}\text { Witness People } \\
\text { People who have watched the intrusions } \\
\text { without losing their former cultural integrity } \\
\text { altogether }\end{array}$ \\
\hline Povos Transplantados & Transplanted People \\
\hline Povos Germinais & Germinal People \\
\hline Processo de Gestação Étnica & Process of Ethnic Gestation \\
\hline Processo Biótico de Consumação dos Negros & $\begin{array}{c}\text { Biological Process of the Consumption of } \\
\text { Blacks }\end{array}$ \\
\hline Processo Biótico de Multiplicação de Mulatos & $\begin{array}{l}\text { Biological Process of Discreet Multiplication } \\
\text { of Mulattos }\end{array}$ \\
\hline $\begin{array}{c}\text { Processo de Reaglutinação das Populações } \\
\text { Caipiras }\end{array}$ & $\begin{array}{c}\text { Process for the Regrouping of Caipira } \\
\text { Population }\end{array}$ \\
\hline Índios Missioneiros Desvirilizados & Tame Missionary Indians \\
\hline Gente Recém-Feita & New Created People \\
\hline Sistema de Reduções & System of Reductions \\
\hline Sistema Granjeiro & System of Farming \\
\hline
\end{tabular}

Nota-se que as traduções correspondem, em sua maioria, a neologismos terminológicos também em LM, representados por explicações teóricas e por inversões, como proposto por Heim e Tymowski (2006). Com isso, observa-se a relação estabelecida entre as escolhas lexicais dos tradutores e a terminologia antropológica em língua inglesa, por meio do cruzamento dos dados do subcorpus de TMs e do subcorpus de TOIs, apresentado na Tabela 10; bem como da busca das expressões em LM na Web, presentes na Tabela 11:

Tabela 10: Expressões fixas e semifixas extraídas dos subcorpora principais em LM as quais podem constituir neologismos terminológicos.

\begin{tabular}{c|c}
\hline $\begin{array}{c}\text { Expressões que podem constituir } \\
\text { neologismos nas obras do corpus de estudo } \\
\text { em LM }\end{array}$ & Ocorrência dos Neologismos nos TOIs \\
\hline Mass of People & Expressão não encontrada \\
\hline New People & New People \\
\hline Darker People & Expressão não encontrada \\
\hline Witness People & Expressão não encontrada \\
\hline
\end{tabular}




\begin{tabular}{c|c}
\hline $\begin{array}{c}\text { People who have watched the intrusions } \\
\text { without losing their former cultural integrity } \\
\text { altogether }\end{array}$ & Expressão não encontrada \\
\hline Transplanted People & Expressão não encontrada \\
\hline Germinal People & Expressão não encontrada \\
\hline Process of Ethnic Gestation & Expressão não encontrada \\
\hline $\begin{array}{c}\text { Biological Process of the Consumption of } \\
\text { Blacks }\end{array}$ & Expressão não encontrada \\
\hline $\begin{array}{c}\text { Process for the Regrouping of Caipira } \\
\text { Population }\end{array}$ & Expressão não encontrada \\
\hline Tame Missionary Indians & Expressão não encontrada \\
\hline New Created People & Expressão não encontrada \\
\hline System of Reductions & Expressão não encontrada \\
\hline System of Farming & Expressão não encontrada \\
\hline
\end{tabular}

Tabela 11: Expressões neológicas ocorrentes nos TMs com o número de frequência na Web.

\begin{tabular}{|c|c|}
\hline $\begin{array}{l}\text { Expressões podem constituir neologismos nas } \\
\text { obras do corpus de estudo em LM }\end{array}$ & $\begin{array}{c}\text { Frequência de ocorrência das expressões } \\
\text { em inglês, na Web }\end{array}$ \\
\hline Mass of People & ) 5.380 .000 \\
\hline New People & 9.730 .000 \\
\hline Darker People & 44.000 \\
\hline $\begin{array}{c}\text { Witness People } \\
\text { People who have watched the intrusions without } \\
\text { losing their former cultural integrity altogether }\end{array}$ & $\begin{array}{r}106.000 \\
\text { Não há ocorrências do conceito }\end{array}$ \\
\hline Transplanted People & 19.300 \\
\hline Germinal People & 376 \\
\hline Process of Ethnic Gestation & 1 \\
\hline Biological Process of the Consumption of Blacks & Não há ocorrências do conceito \\
\hline $\begin{array}{l}\text { Biological Process of Discreet Multiplication of } \\
\text { Mulattos }\end{array}$ & Não há ocorrências do conceito \\
\hline $\begin{array}{c}\text { Process for the Regrouping of Caipira } \\
\text { Population }\end{array}$ & Não há ocorrências do conceito \\
\hline Tame Missionary Indians & Não há ocorrências do conceito \\
\hline New Created People & 10.300 \\
\hline System of Reductions & 35.200 \\
\hline System of Farming & 326.000 \\
\hline
\end{tabular}

No que concerne às traduções, Meggers e Rabassa tendem a realizar criações novas de uma terminologia especializada que se volta para o contexto brasileiro em LM. Sendo assim, são pouco frequentes ou inexistentes os usos das expressões que escolhem como possíveis 
correspondentes aos neologismos darcynianos. No entanto, também ocorrem generalizações terminológicas, de modo que os tradutores buscam ancorar suas escolhas em elementos da linguagem geral, assim como em recursos que procuram apresentar os conceitos de maneira explicativa.

Do mesmo modo, encontram-se termos simples e compostos nas obras de Ribeiro, que podem ser considerados neologismos. Com isso, apresentam-se, abaixo, as Tabelas 12 e 13 com os termos simples e compostos que determinam possíveis neologismos e a relação que estabelecem com o corpus de TOPs:

Tabela 12: Termos simples e complexos extraídos dos subcorpora principais em LF os quais podem constituir neologismos terminológicos.

\begin{tabular}{c|c}
\hline $\begin{array}{c}\text { Termos que podem constituir neologismos } \\
\text { nas obras do corpus de estudo em LF }\end{array}$ & \begin{tabular}{c} 
Ocorrência dos Neologismos nos TOPs \\
\hline Achamento
\end{tabular} \\
\hline Brasil-Povo & Termo não encontrado \\
\hline Caudilho-Estanceiro & Termo não encontrado \\
\hline Comunidades-Feitorias & Termo não encontrado \\
\hline Gentio-Brabo & Termo não encontrado \\
\hline Ilha-Brasil & Termo não encontrado \\
\hline Mameluco-Brasilíndio & Termo não encontrado \\
\hline Meio-Índio & Termo não encontrado \\
\hline Morenização & Termo não encontrado \\
\hline Ninguendade & Termo não encontrado \\
\hline
\end{tabular}

Tabela 13: Termos neológicos ocorrentes nos TFs com o número de frequência na Web.

\begin{tabular}{|c|c|}
\hline $\begin{array}{c}\text { Termos que podem constituir neologismos } \\
\text { nas obras do corpus de estudo em LF }\end{array}$ & $\begin{array}{c}\text { Frequência de ocorrência dos termos em } \\
\text { português, na Web }\end{array}$ \\
\hline Achamento & 85.200 \\
\hline Brasil-Povo & Não há ocorrências do conceito \\
\hline Caudilho-Estanceiro & 3 \\
\hline Comunidades-Feitorias & 5 \\
\hline Gentio-Brabo & 315 \\
\hline Ilha-Brasil & Não há ocorrências do conceito \\
\hline Mameluco-Brasilíndio & 5 \\
\hline Meio-Índio & 12.600 \\
\hline Morenização & 1.100 \\
\hline Ninguendade & 3.540 \\
\hline
\end{tabular}


No âmbito dos termos, nota-se que, entre as construções do autor em LF, sua maioria tende a ser assimilada com maior frequência, apresentando um uso recorrente pelos antropólogos e cientistas sociais brasileiros. Em outros casos, como, por exemplo, no que diz respeito ao conceito de "achamento", observa-se que, embora não ocorra com frequência em obras da área antropológica, Darcy Ribeiro reusa o vocábulo que consta na carta de Pero Vaz de Caminha ao rei, quando do descobrimento do Brasil. Nesse sentido, de acordo com a obra darcyniana, tudo indicava que os portugueses realmente procuravam uma terra e acabaram "achando".

$\mathrm{Na}$ teoria antropológica, o autor considera, no plano econômico, o Brasil enquanto implantação e interação de quatro ordens de ação produtiva, a saber: a empresa escravista, a empresa comunitária jesuítica, a microempresa de produção de subsistência e o núcleo portuário de banqueiros, armadores e comerciantes de importação e exportação, o qual ficava com a maior parte dos lucros. No entanto, o grupo fundador do "Brasil-povo", para o teórico, constituiu-se entre os "micro-produtores de subsistência", visto que estes, por serem mais estáveis, gestaram as células que, multiplicadas, resultaram na formação do povo brasileiro. Para Ribeiro,

As empresas de subsistência viabilizaram a sobrevivência de todos e incorporaram os mestiços de europeus com índios e com negros, plasmando o que viria a ser o grosso do povo brasileiro [grifo nosso]. Foram, sobretudo, um criatório de gente. Com efeito, o corpo do Brasil rústico, seus tecidos constitutivos - carne, sangue, ossos, peles -, se estrutura, nessas microempresas de subsistência, configuradas nas diversas variantes ecológico-regionais. É sobre esse corpo, como mecanismo de sucção de sua substância, mas também de ejeção sobre ele da matéria humana emprestável para seus fins mercantis, que se instalam, como carcinomas, as empresas agroexportadoras e mineradoras (RIBEIRO, 1995, p.177).

Desse modo, o conceito de "Brasil-povo" estabelece uma conexão com os processos de "desafricanização" e "desindianização", os quais representam etapas do apagamento das identidades e da recriação da etnicidade por meio da "transfiguração étnica" (descrita anteriormente). Contudo, tal "etnicidade" apresenta-se como englobadora, pois funde uma "[...] crescente massa humana que perdera a cara: eram ex-índios desindianizados, e, sobretudo, mestiços, mulheres negras e índias, muitíssimas, com uns pouquíssimos brancos europeus que nelas se multiplicavam prodigiosamente" (RIBEIRO, 1995, p.447).

Nesse contexto, ocorre, ainda, o que Darcy Ribeiro chama de "destribalização" e formação das "Ilhas-Brasil”". O "índio" é retirado de seu habitat nativo e de suas relações 
parentais, sociais, culturais e recolocado, juntos com os outros núcleos fundadores da nação, nas "Ilhas-Brasil".

Essa etnia embrionária, multiplicada e difundida em vários núcleos - primeiro ao longo da costa atlântica, depois transladando-se para os sertões interiores ou subindo pelos afluentes dos grandes rios -, é que iria modelar a vida social e cultural das ilhas-Brasil. Cada uma delas singularizada pelo ajustamento às condições locais, tanto ecológicas quanto de tipos de produção, mas permanecendo sempre como um renovo genésico da mesma matriz.

Essas ilhas-Brasil operaram como núcleos aglutinadores e aculturadores dos novos contingentes apresados na terra, trazidos da África ou vindos de Portugal e de outras partes, dando uniformidade e continuidade ao processo de gestação étnica, cujo fruto é a unidade sociocultural básica de todos os brasileiros (RIBEIRO, 1995, p.269).

Forma-se um povo totalmente novo que se organiza em "protocélulas étnicas neobrasileiras” de "não-índios", “não-negros”, "não-europeus” (ou seja, "protobrasileiros”), influenciados pelo sentimento de não-pertencimento, a "ninguendade".

É importante notar que Darcy Ribeiro (1995, p.116) descreve, também, o "brasilíndio" e sua relação com o processo de "ninguendade". Em O povo brasileiro, nota-se que as reflexões antropológicas atrelam os neologismos de modo que cada nossa acepção criada por Darcy Ribeiro estabelece um vínculo com a anterior, assim sendo, o "brasilíndio" é um "não-índio", mestiçado para a formação do "Brasil-povo", realocado nas "Ilhas-Brasil" e transfigurado na busca por uma etnicidade brasileira. $\mathrm{O}$ autor afirma que:

[...] o brasilíndio, como o afro-brasileiro, existiam numa terra de ninguém, etnicamente falando, e é a partir dessa carência essencial, para livrar-se da ninguendade de não-índios, não-europeus, não-negros, que eles se vêem forçados a criar sua própria identidade étnica: a brasileira (RIBEIRO, 1995, p.132).

O teórico confere, por conseguinte, à "ninguendade" o papel de elemento fomentador da constituição do povo brasileiro, ao lado de outros fatores como as heranças e as adaptações dos povos indígenas e africanos às condições sociais, econômicas e culturais que formam o amálgama de uma sociedade reordenada.

Quanto ao processo tradutório, abaixo, nas tabelas 14 e 15, apresentam-se as traduções dos termos neológicos de Darcy Ribeiro e sua ocorrência na Web: 
Tabela 14: Exemplos de traduções de termos neológicos darcynianos apresentados por Meggers e Rabassa.

\begin{tabular}{|c|c|}
\hline $\begin{array}{c}\text { Termos que podem constituir neologismos nas } \\
\text { obras do corpus de estudo em LF }\end{array}$ & $\begin{array}{c}\text { Possíveis traduções realizadas por Betty } \mathbf{J} . \\
\text { Meggers e Gregory Rabassa }\end{array}$ \\
\hline Achamento & $\begin{array}{c}\text { Finding } \\
\text { Discovery } \\
\end{array}$ \\
\hline Brasil-Povo & Brazil as a People \\
\hline Caudilho-Estanceiro & Rancher-Chieftain \\
\hline Comunidades-Feitorias & Trading-Post Communities \\
\hline Gentio-Brabo & Heathen \\
\hline Ilha-Brasil & $\begin{array}{c}\text { Island that make up Brazil } \\
\text { Islands-Brazil }\end{array}$ \\
\hline Mameluco-Brasilíndio & Brazilindian Mameluco \\
\hline Meio-Índio & Half-Indian \\
\hline Morenização & \\
\hline Ninguendade & Nobodyness \\
\hline
\end{tabular}

Tabela 15: Expressões neológicas ocorrentes nos TMs com o número de frequência na Web.

\begin{tabular}{c|r}
\hline $\begin{array}{c}\text { Termos que podem constituir neologismos } \\
\text { nas obras do corpus de estudo em LM }\end{array}$ & $\begin{array}{r}\text { Frequência de ocorrência dos termos em } \\
\text { inglês, na Web }\end{array}$ \\
\hline Finding & 906.000 .000 \\
Discovery & 513.000 .000 \\
\hline Brazil as a People & 12.800 \\
\hline Rancher-Chieftain & 9 \\
\hline Trading-Post Communities & 2.070 \\
\hline Heathen & Não há ocorrências do conceito \\
\hline Island that make up Brazil & 2 \\
\hline Islands-Brazil & Não há ocorrências do conceito \\
\hline Half-Indian & 1.100 .000 \\
\hline Darkening & 1.400 .000 \\
\hline Nobodyness & 18.700 \\
\hline
\end{tabular}

A tradução dos neologismos darcynianos revela o diálogo que se estabeleceu entre TF e TM, visto que Rabassa e Meggers conseguem depreender, do léxico de Darcy Ribeiro, conhecimento suficiente para elaborar neologismos adaptados à LM, como por exemplo: Brazilindian, de-indianized, de-indianization, nobodyness e protoBrazilian. Os tradutores mantêm estreita relação com o TF, embora tenha sido salientado que a obra darcyniana e sua tradução fomentam funções sociais distintas amoldadas a cada cultura e sociedade em que circulam. 
Verifica-se, também, que houve variação na criação dos novos termos em LM somente no exemplo do termo composto "ilhas-Brasil", que apresenta as traduções islands-Brazil e islands that make up Brazil. Neste caso específico, o tradutor recorreu à elaboração de um termo novo, seguida de uma explicitação. Nos demais exemplos, uma vez elaborado o neologismo, Rabassa manteve-o, revelando, com isso, a necessidade de manter a coerência teórica de Darcy Ribeiro também no TM.

De modo geral, os termos e expressões cunhados por Darcy Ribeiro ficam no plano da pesquisa antropológica, adicionando, muitas vezes, aos termos "Brasil" e "brasileiro" outros vocábulos que vão determinar situações comuns ao ambiente, sociedade e cultura nacional, como em: "Brasil-povo", "brasilíndio", “ilhas-Brasil”, "protobrasileiro" e "protocélula étnica neobrasileira".

Além disso, por meio da análise dos TMs de Meggers e Rabassa, nota-se que, embora exista uma terminologia comum aos cientistas sociais, não há consenso quanto a seu uso, principalmente se colocarmos em pauta as trocas culturais e os valores que envolvem o intercâmbio de informações sociais entre a Cultura Fonte e a Cultura Meta.

A partir dos exemplos apresentados, observa-se que o trabalho dos tradutores revela um avanço na tendência de permitir a introdução de novos conceitos ao contexto da produção dos TMs, considerando ainda as diferenças de sentido implícitas na própria linguagem. Tal “disposição permissiva" pode ser vista nos Estudos da Tradução que apontam para um processo tradutório relacionado à intencionalidade do autor e do tradutor (NORD. 2001). Sendo assim, considerando que o objetivo dos textos darcynianos foi explorar a formação do povo brasileiro, é bastante plausível que os tradutores busquem atrelar os TMs às teorizações dos TFs, o que é corroborado por meio das análises desenvolvidas no presente trabalho por meio das contribuições da Linguística de Corpus.

Nota-se, assim, que a tradução dos neologismos mostra-se mais próxima das áreas de especialidade, havendo uma adequação de características culturais e mesmo terminológicas no texto de Meggers, ao passo que Rabassa parece refletir sobre as opções lexicais que se apresentam em língua inglesa, recorrendo à explicação e à explicitação dos constructos e ideários darcynianos. 


\section{Considerações Finais}

O software WordSmith Tools, por meio de suas ferramentas, facilita consideravelmente a análise de uma grande quantidade de dados, obtidos de maneira muito mais rápida e exata do que manualmente. A consulta ao corpus de apoio é essencial para estudos desta natureza. Alguns termos e expressões considerados como neologismos e levantados nos corpora principais apresentam possibilidades de diferentes correspondentes em língua inglesa, como por exemplo, no caso da expressão "povo testemunho", que apresentou duas possibilidades de correspondência: witness people (utilizada por Meggers) e people who have watched the intrusions without losing their former cultural integrity altogether (utilizada por Rabassa).

As diversas opções dos tradutores apontam variações de uso nas escolhas lexicais, evidenciando, possivelmente, tentativas de apresentar ao público alvo a versatilidade da sociedade no Brasil e, assim, desenhar, de uma maneira mais ampla, o contexto em que eles representam as diferentes facetas da cultura e língua brasileiras.

É preciso salientar, também, que, ao longo dessa pesquisa, verifica-se a intensa produção de neologismos terminológicos e de releituras conceituais no âmbito das expressões fixas e semifixas. Em decorrência da grande criação conceitual em Ciências Sociais e, principalmente em $A C$, boa parte dos termos e expressões não consta em dicionários especializados, tornando a busca por correspondentes difícil para os tradutores. Dessa forma, evidencia-se a validade da compilação de glossários bilíngues nesse campo, a fim de constituir bases de pesquisa para a produção tradutória.

Observa-se ainda, as possíveis alterações de sentido contidas nas escolhas lexicais de autor e tradutores para termos e expressões frequentes em textos das Ciências Sociais e da Antropologia, como por exemplo: "consanguinidade", "exogamia", "escravismo", "família" e "parentesco"; e para neologismos terminológicos, como: "brasilíndio", "Brasil-povo", "ilhasBrasil", "ninguendade" e "protobrasileiro". Com isso, procura-se encontrar as bases formadoras para o processo tradutório para uma terminologia nova.

Ao serem comparados os termos mais frequentes e os neologismos em Língua Portuguesa, bem como seus correspondentes em Língua Inglesa, empregados pelos tradutores, aos termos comumente utilizados por autores que escrevem originalmente nesses idiomas, encontra-se o desenvolvimento de interação teórica rica entre os antropólogos e cientistas sociais brasileiros e estrangeiros. 
Pode-se dizer que, nas obras dos corpora em análise, não existe uma definição de sociedade que seja única e aceita de modo geral, pois cada grupo humano organiza-se de maneiras distintas e vê o mundo sob diferentes perspectivas. De maneira geral, os estudiosos das Ciências Sociais procuram estabelecer uma totalidade das relações sociais entre as criaturas humanas, e a terminologia concernente ao panorama geral dos conhecimentos socioculturais torna-se, de certa forma, padrão. No entanto, quando se trata de um núcleo neológico, há alternância na escolha de termos, ficando mais evidente em elementos que são marcados socialmente por valores folclóricos e representações de atos, atores e lugares culturalmente apresentados.

Dessa forma, diante dos resultados obtidos, espera-se que este estudo possa oferecer uma contribuição para os Estudos da Tradução baseados em Corpus e para a Linguística de Corpus. Espera-se também que os dados aqui apresentados possam fornecer subsídios a professores, pesquisadores, tradutores, alunos de tradução, bem como profissionais da área de Ciências Sociais, no sentido de promover a conscientização acerca das diferenças socioculturais contidas no léxico de especialidade além de oferecer material de suporte para futuras traduções e pesquisas na área antropológica e social.

\section{Referências bibliográficas}

AKOUN, A. Dicionário de Antropologia: do homem primitivo às sociedades actuais. (Trad. de Germiniano Cascais Franco. Lisboa: Verbo, 1983.

ALVES. A delimitação da unidade lexical nas línguas de especialidade. Palavra, 5, 1999, pp. 69-80.

AUBERT, F.H. et.al. Descrição e quantificação de dados em tradutologia. Tradução e Comunicação. n. 4, São Paulo: Álamo, 1984.

BAKER, M. In other words: a coursebook on translation. London and New York: Routledge, 1992. cross $\boldsymbol{r e f}_{\mathrm{http}: / / \mathrm{dx} . \mathrm{doi} .0 \mathrm{gg} / 10.1075 / \mathrm{btl} .22}$

. Corpus linguistics and translation studies: implications and applications. In BAKER, M.; FRANCIS, G.; TOGNINI-BONELLI, E. (Org.). Text and technology: in honour of John Sinclair. Amsterdam: John Benjamins. 1993, p. 233-250.

Corpora in translation studies: an overview and some suggestions for future research. Target, Amsterdam, v. 7. n2. 1995, p. 223-243. 
. Corpus-based translation studies: the challenges that lie ahead. In: SOMERS, Herald. (Ed). Terminology, LSP and translation studies in language engineering: in honour of Juan C. Sager. Amsterdam: John Benjamins. 1996, p. 177-186.

Towards a Methodology for investigation the style of literary translation. Target, Amsterdã, V. 12, n. 2. 2000, p.241-266.

BARFIELD, T. The Dictionary of Anthropology. Oxford: Blackwell Publishing Ltda., 1997.

BARROS, L. A. Curso básico de Terminologia. São Paulo: EDUSP, 2004.

BERBER SARDINHA, T. Lingüística de Corpus. Barueri, SP: Manole, 2004.

BOULANGER, J. C. L'évolution du concept de NEOLOGIE de la linguistique aux industries de la langue. In: SCHAETZEN, C. de. Terminologie anachronique. Paris: Conseil Internacional de la Langue Française, 1989. p.193-211.

CABRÉ, M. T. La terminología, teoría, metodología, aplicaciones. Barcelona: Antártida, 1993. . La terminología: representación y comunicación. Barcelona: Institut Universitari de Linguística Aplicada, 1999.

CAMARGO, D. C. de. Contribuição para uma tipologia da tradução: as modalidades de tradução no texto literário. Tese (Doutorado) FFLCH, Universidade de São Paulo, São Paulo, 1993.

Padrões de estilo de tradutores: um estudo de semelhanças e diferenças em corpora de traduções literárias, especializadas e juramentadas. 512 f. Tese (Livre-Docência em Tradução) - Instituto de Biociências, Letras e Ciências Exatas - Unesp, Universidade Estadual Paulista, São José do Rio Preto, 2005.

. Metodologia de pesquisa em tradução e linguística de corpus. São Paulo: Cultura Acadêmica/São José do Rio Preto: Laboratório Editorial. (Coleção Brochuras,v.1) 2007.

CARDoso, F. H.; FALETTO, E. Dependência e desenvolvimento na América Latina: ensaio de interpretação sociológica. 7 ed. Rio de Janeiro: LTC, 1996, 144p.

CHESTERMAN, A. Memes of translation: the spread of ideas in translation theory. Amsterdam: John Benjamins, 1997. cross ref $\underline{\text { http://dx.doi.org/10.1075/bt1.22 }}$

DAMATTA, R. O que faz o Brasil, Brasil? 8.ed. Rio de Janeiro: Rocco, 1997.

DICIONÁRIO DE CIÊNCIAS SOCIAIS. Rio de Janeiro: Editora Fundação Getúlio Vargas, 1986.

DICIONÁRIO DE SOCIOLOGIA. $7^{\circ}$ ed. Porto Alegre: ed. Globo, 1977.

EVEN-ZOHAR, I. The position of translated literature within the literary polisystem. In: HOLMES, J.; LAMBERT, J.; VAN DEN BROECK, R. (Ed.). Literature and translation. 
Leuven, 1978, p. 83-100, [Versão revisada em VENUTI, L. (Ed.). The translation studies reader. London/New York: Routledge, 2000, p.198-211]

FERNANDES, F. A revolução burguesa no Brasil: ensaio de interpretação sociológica. São Paulo: Globo, 1975.

HEIM, M. H.; TYMOWSKI, A. Guideliness for the Translation of Social Science Texts. Nova Iorque: American Council of Learned Societies, 2006.

ORENHA-OTTAIANO, A . A compilação de corpora comparáveis na área de negócios e sua relevância para a tradução e terminologia. Calidoscópio (UNISINOS), v. 07, p. 232-236, 2009. cross $^{\text {ref }}$ http://dx.doi.org/10.4013/cld.2009.73.06

PAIVA, P. T. P. ; XATARA, C. M. ; CAMARGO, D. C. Uma reflexão sobre a elaboração de um léxico bilíngüe preliminar na subárea de cardiologia a partir do uso de termos econtrados em um corpus paralelo e em dois corpora comparáveis. DELTA. Documentação de Estudos em Linguística Teórica e Aplicada (PUCSP. Impresso), v. 24:1, p. 1-22, 2008.

.; CAMARGO, D. C. Estudos da tradução baseados em corpus e lingüística de corpus: levantamento de termos médicos para a elaboração de um glossário bilíngüe. Estudos Lingüísticos (São Paulo), v. 2, p. 428-436, 2007.

NORD, C. Translating as a Purposeful Activity - Functionalism Approaches Explained. St. Jerome Publishing: Manchester, UK \& Northampton MA, 2001.

RIBEIRO, D. O processo Civilizatório. Rio de Janeiro: Editora Civilização Brasileira S.A., 1968.

. The Civilizational Process. Translated by Betty M. Meggers. Washington: Smithsonian Institution Press, 1968.

1995.

. O povo brasileiro: a formação e o sentido do Brasil. São Paulo: Companhia das Letras,

The Brazilian People: formation and meaning of Brazil, Translated by Gregory Rabassa. Gainesville: University Press of Florida, 2000.

ROCHA, J. M. P.; ORENHA-OTTAIANO, A. Colocações especializadas na área médica extraídas a partir do corpus house MD. Cadernos do IL, v. 44, p. 295-318, 2012.

SCHLEIERMACHER, F. Sobre os diferentes métodos de tradução. Tradução de Margarete von Mühlen Poll. Clássicos da Teoria da Tradução -Antologia bilíngüe / Alemão-Português. Werner Heidermann, org. Florianópolis: UFSC, Núcleo de tradução, 2001.

SINCLAIR, J. M. Corpus, concordance, collocation. Oxford: Oxford, 1991.

TAGNIN, S. E. O. Corpus-driven terminology in Brazil. Cahiers de Lexicologie (Paris), v. 101, p. 169-180, 2012. 
TOURY, G. The nature and role of norms in literary translation. In: HOLMES, J.; LAMBERT, J; VAN DEN BROECK, R. (Ed.). Literature and translation. Leuven: ACCO, 1978 p. 83-100 [Versão revisada em VENUTI, L. (Ed.). The translation studies reader. London/New York: Routledge, 2000, p. 205 -218].

Artigo recebido em: 20.11.2013

Artigo aprovado em: 27.01.2014 